\title{
PENGARUH MODEL PEMBELAJARAN INKUIRI TERBIMBING BERBANTUAN LABORATORIUM VIRTUAL TERHADAP KEMAMPUAN REPRESENTASI GRAFIK SISWA SMA DI SEKOLAH
}

\author{
${ }^{1)}$ Laily Ahila Qurrotul Firdausi, 1)I Ketut Mahardika, ${ }^{1)}$ Supeno \\ ${ }^{1)}$ Program Studi Pendidikan Fisika FKIP Universitas Jember \\ Email: lailyahila02@gmail.com
}

\begin{abstract}
The purpose of this study was to determine the effect of the guided inquiry learning model assisted by a virtual laboratory on the graphic representation ability of high school students in schools. The multi-representation used in this study is a graphical representation. This study uses a quasi-experimental method with a post test only design. The sample used in this study was taken by purposive sampling technique. This research was conducted at SMAN Pakusari with the research subjects of class X MIA 4 as the experimental class and class $X$ MIA 1 as the control class. The data collection technique uses tests, the tests in this study as data collection containing questions / exercises that are used to measure the ability of graphic representation owned by each individual. Based on the results of the $t$ test, with the 2 independent sample t-test or MannWhitney $U$ test, it can be seen that the output of the Statistic Test for the asymp value. Sig. (2-tailed) that is $0.002<0.05$ so that there is a significant effect between the ability of graphic representation in the experimental class and the control class.
\end{abstract}

Key word: Guided Inquiry, Virtual laboratorium, Graph Multirepresentation Skill

\section{PENDAHULUAN}

Pendidikan merupakan pondasi penting bagi kemajuan suatu bangsa dan negara. Perkembangan dan kemajuan segala bidang ditentukan oleh keberhasilan pendidikan sehingga kualitas pendidikan saat ini harus selalu ditingkatkan. Dalam proses pendidikan sendiri harus dilakukan oleh usaha sadar manusia yang bersifat terencana dan kontinyu. Terencana mengandung arti bahwa pelaksanaan pendidikan harus direncanakan dengan matang, bertahap, bertujuan jelas dan berdasarkan pemikiran rasional-objektif. Sedangkan berlangsung kontinyu berarti pendidikan dilaksanakan secara terus menerus tidak akan berakhir selama manusia hidup. Untuk meningkatkan kualitas pendidikan peru dilaksanakannya pembelajaran yang berkualitas sehingga dalam proses pembelajaran perlu adanya penyusunan tujuan pembelajaran yang tepat, salah satu tujuan pembelajaran fisika di SMA adalah mengembangkan kemampuan multirpresentasi siswa dengan menggunakan model pembelajaran inkuiri terbimbing berbantuan virtual laboratorium. Penggunaan model inkuiri terbimbing diharapkan dapat melatihkan kemampuan multirepresentasi pada setiap fase model inkuiri terbimbing. Pada tahap mengkomunikasikan informasi siswa dituntut untuk menggunakan semua 
pengetahuan direpresentasikan dalam berbagai representasi agar hasil proses inkuiri dapat disajikan secara valid (David, 2006). Representasi dalam pembelajaran fisika dapat digunakan untuk meminimalisasi kesulitan siswa dalam belajar fisika. Sebagaimana dinyatakan Brenner (dalam Kartini 2009) bahwa proses pemecahan masalah yang sukses bergantung kepada keterampilan merepresentasi masalah seperti mengonstruksi dan menggunakan representasi matematik di dalam kata-kata, grafik, tabel dan persamaan- persamaan, penyelesaian dan manipulasi simbol. Hal ini dikarenakan multirepresentasi dapat memberikan tiga manfaat utama yaitu sebagai pelengkap informasi, pembatas interpretasi dan pembangun pemahaman (Ainsworth 1999). Dalam pembelajaran, siswa dituntut untuk menguasai representasi-representasi berbeda seperti hasil percobaan, grafik, konseptual, rumus, gambar, diagram (Mahardika, 2013). Cara penyajian seperti ini sangat sesuai digunakan pada pembelajaran fisika terutama materi Hukum Newton yang banyak menggunakan representasi grafik untuk membentuk persamaan baru.

Kemampuan representasi grafik, Wavering (Nasution, 2000), menyatakan bahwa grafik merupakan alat bantu yang digunakan dalam sains untuk membeberkan data dan menolong dalam suatu analisis hubungan diantara variable-variabel. Sementara Soedarso (1999) mengemukakan bahwa grafik memungkinkan penyampaian ide yang kompleks secara lebih sederhana, sekaligus dapat mengikhtisarkan suatu informasi. Artinya grafik dapat digunakan untuk meringkas penyajian materi, tanpa menghilangkan isi konsep dari bahan ajar yang disiapkan.

Surakhmad (Koentjaraningrat, 1986) menyatakan bahwa kelebihan penggunaan grafik dalam menjelaskan hubungan berbagai konsep yaitu: (1) grafik dapat menyajikan data secara lebih jelas, padat, singkat dan sederhana daripada penyampaian informasi secara uraian tertulis; (2) grafi k dapat menonjolkan sifatsifat khas dari data dengan lebih jelas daripada melalui uraian tertulis. Selanjutnya Dickinson \& Hook (Roslina, 1997), diantaranya menyebutkan empat kegunaan grafi $k$ yaitu: (1) grafik dapat membangkitkan minat pembaca terhadap materi-materi yang disajikan; (2) grafik dapat mengklasifi kasikan, menyederhanakan lebih banyak informasi dari materi yang disajikan; (3) grafi $\mathrm{k}$ dapat membantu hal-hal yang dirujuk dalam buku teks atau penyajian; (4), grafi $\mathrm{k}$ juga merupakan bagian statistik bagi para pengguna lainnya. Terkait penggunaan multirepresentasi, Ainsworth (2006) menyatakan bahwa multiplerepresentations can be used so that one representation constrains interpretations of another one. Often learners can fi nd a new form of representation complex and can misinterpret it. In this case one might use a second, more familiar or easy to interpret, representation to support learners' understanding of new complicated representation. Dalam konteks pelayanan komprehensif terhadap seluruh mahasiswa, penggunaan multirepresentasi juga sangat mendukung. Seperti telah diungkapkan pada bagian pendahuluan bahwa setiap peserta didik (siswa atau mahasiswa) memiliki kemampuan spesifik yang berbeda antara satu dengan lainnya, ada yang lebih menonjol kemampuan verbalnya, ada yang lebih menonjol kemampuan spasial dan kuantitatifnya, ada yang lebih menonjol kemampuan visual dan grafisnya. Penampilan berbagai representasi pada penjelasan suatu konsep tentu akan memberi kesempatan kepada para mahasiswa untuk dapat memahami konsep dari berbagai representasi sesuai dengan kemampuan sfesifiknya. 


\section{METODE}

Jenis metode penelitian yang dilakukan adalah kuasi eksperimen. Penelitian kuasi eksperimen merupakan penelitian dengan menggunakan pengembangan dari true experimental design. Metode ini digunakan untuk mencari pengaruh perlakuan tertentu terhadap kelas yang terkendalikan. Penelitian dilaksanakan untuk mengetahui besarnya pengaruh model inkuiri terbimbing berbantuan laboratorium virtual terhadap kemampuan representasi grafik pada pembelajaran hukum newton dengan menggunakan desain Post Test only model pembelajaran inkuiri terbimbing untuk mengukur kemampuan representasi grafik siswa.

$\begin{array}{lll}\mathrm{R} 1 & \mathrm{X} & \mathrm{O} 1\end{array}$

\begin{tabular}{ll}
$\mathrm{R} 2$ & $\mathrm{O} 2$ \\
\hline
\end{tabular}

Gambar 1 Desain penelitian post test only control design

Keterangan:

$\mathrm{R} 1$ = Kelas Eksperimen

R2 = Kelas Kontrol

$\mathrm{X}=$ Perlakuan eksperimen, menggunakan model pembelajaran Guided Inquiry (Inkuiri Terbimbing)

O1 = Hasil Post-test Kelas Eksperimen

$\mathrm{O} 2=$ Hasil Post-test Kelas Kontrol

(Sugiyono, 2014: 112)

Penentuan tempat penelitian dengan menggunakan metode purposive sampling area, dimana daerah tersebut sengaja dipilih dengan tujuan dan pertimbangan tertentu, diantaranya yaitu keterbatasan waktu, tenaga keadaan covid. Penelitian dilaksanakan di SMA Negeri Pakusari pada semester genap tahun ajaran 2019/2020. Kelompok pertama diberi perlakuan $(\mathrm{X})$ berupa model pembelajaran inkuiri terbimbing berbantuan laboratorium virtual dan kelompok yang lain tidak. Kelompok yang diberi perlakuan disebut kelompok eksperimen dan kelompok yang tidak diberi perlakuan disebut kelompok kontrol.

Teknik analisis data yang digunakan yaitu mengkaji pengaruh signifikansi model pembelajaran inkuiri terbimbing terhadap kemampuan representasi grafik siswa dalam pembelajaran hukum newton di SMA menggunakan uji Independent Samples t-test apabila data berdistribusi normal dengan bantuan SPSS 25. Pengujian hipotesis dilakukan dengan persamaan sebagai berikut:

nilai $(\%)=\frac{\text { skor yang dijawab benar }}{\text { jumlah shor total }} x 100 \%$

Tabel 1. Kriteria Kemampuan multirepresentasi

\begin{tabular}{cc} 
Siswa & Kategori \\
\hline Nilai (\%) & Baik sekali \\
\hline $81-100$ & Baik \\
\hline $61-80$ & Cukup \\
\hline $41-60$ & Kurang \\
\hline $21-40$ & Sangat kurang \\
\hline $0-20$ & (Arikunto, 2016)
\end{tabular}

\section{HASIL DAN PEMBAHASAN}

Pembelajaran dilaksanakan secara online dengan menggunakan aplikasi Zoom dan Edmodo dikarenakan adanya pandemi COVID-19. Pertemuan pertama dilakukan dengan menerapkan model pembelajaran inkuiri terbimbing pada kelas X MIPA 4 yang berisi 36 siswa, namun terdapat satu siswa tidak mengikuti pembelajaran online. Pembelajaran tersebut berlangsung pada 
aplikasi Zoom selama 40 menit dengan menerapkan sintaks dari model pembelajaran inkuiri terbimbing. Langkah pertama dalam pembelajaran ini adalah guru menyajikan pertanyaan atau masalah yang berkaitan dengan materi hukum Newton dimana guru membimbing siswa mengidentifikasi masalah serta guru membagi siswa dalam kelompok. Siswa dibagi kedalam 7 kelompok, dimana satu kelompok terdiri dari 5-6 siswa. Selanjutnya siswa melakukan praktikum sesuai dengan materi yang diberikan dengan mengikuti langkah-langkah penyelesaian sesuai yang tertera pada LKS selanjutnya tahap membuat hipotesis, yaitu guru memberikan kesempatan pada siswa untuk merumuskan hipotesis atas pertanyaan atau solusi permasalahan yang dapat diuji dengan kata. Untuk memudahkan proses ini, guru menanyakan kepada siswa gagasan hipotesis yang mungkin. Dari semua gagasan yang ada, dipilih salah satu hipotesis yang relevan dengan permasalahan yang diberikan. Siswa mencatat informasi serta data yang di dapat selama melaksanakan percobaan. Langkah berikutnya menganalisis data, siswa bertanggung jawab menguji hipotesis yang telah dirumuskan dengan menganalisa data yang telah diperoleh. Faktor penting dalam menguji hopotesis adalah pemikiran benar atau salah. Setelah memperoleh kesimpulan dari data percobaan, siswa dapat menguji hipotesis yang telah dirumuskan. Apabila hipotesis itu salah atau ditolak, siswa dapat menjelaskan sesuai dengan proses inkuiri yang telah dilakukannya. Langkah penutup yaitu membuat kesimpulan sementara berdasarkan data yang diperoleh siswa.

Dari hasil data diperoleh nilai rata-rata kemampuan representasi grafik tertinggi dan terendah. Kemampuan representasi grafik pada kelas eksperimen memiliki rata-rata nilai sebesar 90. Hal ini disebabkan siswa pada kelas eksperimen mendapat perlakuan pembelajaran materi hukum Newton berbantuan virtual laboratorium dimana siswa melakukan praktikum melalui aplikasi virtual laboratorium tanpa akses internet sehingga siswa tersebut tidak perlu hadir untuk mengikuti praktikum di ruang laboratorium. Hal ini dapat menjadi pembelajaran efektif karena siswa dapat belajar sendiri secara aktif tanpa bantuan instruktur ataupun asisten seperti sistem berjalan (Puspita, 2008).

Data hasil kemampuan representasi grafik awal siswa pada penelitian diperoleh dari post-test yaitu data setelah peneliti melakukan pembelajaran pada kedua kelas. Data hasil post-test selengkapnya dapat dilihat pada lembar lampiran, dan berikut adalah Tabel 2 tentang data hasil post-test kelas eksperimen dan kelas kontrol untuk representasi grafik:

Tabel 2. Data hasil post-test representasi grafik

\begin{tabular}{lll}
\hline & $\begin{array}{l}\text { Kelas } \\
\text { Eksperimen }\end{array}$ & $\begin{array}{l}\text { Kelas } \\
\text { Kontrol }\end{array}$ \\
\hline $\begin{array}{l}\text { Jumlah } \\
\text { siswa }\end{array}$ & 36 & 36 \\
\hline $\begin{array}{l}\text { Nilai } \\
\text { tertinggi }\end{array}$ & 100 & 100 \\
\hline $\begin{array}{l}\text { Nilai } \\
\text { terendah }\end{array}$ & 60 & 40 \\
\hline Rata-rata & 90 & 77,22 \\
\hline $\begin{array}{l}\text { Standar } \\
\text { deviasi }\end{array}$ & 12,18 & 18,61 \\
\hline
\end{tabular}

Berdasarkan data yang terlihat pada Tabel 2 dapat diketahui bahwa kemampuan siswa dalam membuat grafik pada kelas eksperimen dan kelas kontrol memiliki nilai rata-rata yang berbeda. Nilai rata-rata kelas eksperimen sebesar 90 sedangkan kelas kontrol sebesar 77,22. Selanjutnya, data dianalisis dengan dilakukannya uji normalitas dan dilanjutkan dengan uji $t$ dengan bantuan aplikasi SPSS 25. Pada uji normalitas menggunakan one sample Kolmogorov- smirnov test menunjukkan 
hasil tidak terdistribusi normal sehingga dilakukan dengan uji 2 Independent sample $t$ test. Hasil dari analisis selengkapnya menggunakan aplikasi dapat dilihat pada lembar lampiran, dan hasil berikut adalah pada Tabel 4.6 ringkasan hasil uji $\mathrm{t}$ menggunakan uji 2 independent samples $t$ test atau Mann-Whitney $U$ test.

Tabel 3. Hasil uji t nilai post-test representasi grafik

Ranks

\begin{tabular}{lllll} 
& KELAS & $\mathrm{N}$ & Mean Rank & Sum Of Ranks \\
\hline \multirow{2}{*}{ Grafik } & Kontrol & 36 & 29.47 & 1061.00 \\
\cline { 2 - 5 } & Eksperimen & 36 & 43.53 & 1567.00 \\
\cline { 2 - 4 } & Total & 72 & & \\
\hline Test Statistics & & \\
& & GRAFIK & \\
\hline Mann-Whitney U & 395.000 & \\
\hline Wilcoxon W & 1061.000 \\
\hline Z & -3.063 & \\
\hline Asymp. Sig. (2-Tailed) & .002 & \\
\hline
\end{tabular}

Berdasarkan hasil uji t, dengan uji 2 independent sample t-test atau MannWhitney $U$ dapat diketahui output Tes Statistic untuk nilai asymp. Sig. (2-tailed) yaitu $0,002<0,05$. Pengujian hipotesis menggunakan pihak kanan, dengan nilai signifikansi (1-tailed) yaitu $0,001 \leq 0,05$, sehingga $\mathrm{H}_{0}$ ditolak dan $\mathrm{H}_{\mathrm{a}}$ diterima. Berdasarkan data tersebut, dapat dikatakan bahwa ada pengaruh yang signifikan antara kemampuan representasi grafik pada kelas eksperimen dengan kelas kontrol. Oleh karena itu, maka rumusan masalah dapat dijawab, yaitu ada pengaruh model pembelajaran inkuiri terbimbing berbantuan virtual laboratorium terhadap kemampuan representasi grafik siswa dalam pembelajaran hukum newton di SMA.

Pada kelas kontrol, indikator kemampuan representasi grafik memiliki nilai rata-rata sebesar 77,2. Hasil yang diperoleh berbeda jauh dengan nilai rata-rata pada kelas eksperimen, hal ini dikarenakan sifat kedua kelas homogen sehingga kemampuan yang dimiliki cenderung sama. Siswa pada kelas kontrol memahami materi hukum Newton dengan baik sehingga dapat memberikan penjelasan secara grafik dengan baik mengenai soal post-test pada indikator kemampuan representasi grafik yang diberikan. Pada kelas kontrol, indikator kemampuan multirepresentasi pada representasi grafik memiliki nilai terendah 40 dalam kategori kurang, dibandingkan dengan nilai terendah kemampuan representasi verbal kelas eksperimen sebesar 60. Hal ini dikarenakan pada saat pembelajaran pada kelas kontrol siswa kurang berperan aktif sehingga siswa masih kesulitan dalam menyatakan konsep fisika melalui penjelasan berupa grafik sebagai alat atau sarana untuk mengungkapkan atau memvisualisasikan pernyataan verbal yang kompleks serta menjelaskan data eksperimen yang terkumpul dan untuk mencapai kesimpulan yang spesifik perlu dilakukan pencatatan data secara teratur, mengklasifikasi dan mentransformasinya ke dalam grafik agar menjadi jelas hubungannya. Hal ini dikarenakan siswa pada kelas kontrol belum dapat memahami keseluruhan materi yang diberikan. 


\section{SIMPULAN DAN SARAN}

Berdasarkan hasil analisis data yang diperoleh, maka disimpulkan bahwa kemampuan representasi grafik siswa selama pembelajaran fisika pada materi hukum Newton terdapat perbedaan yang signifikan pada hasil kemampuan representasi grafik menggunakan model pembelajaran inkuri terbimbing berbantuan virtual laboratorium dalam pembelajaran fisika di SMA. Berdasarkan hasil penelitian dan pembahasan, maka saran yang diberikan adalah dapat dijadikan sebagai bahan pertimbangan untuk penelitian selanjutnya dengan materi ataupun mata pelajaran yang berbeda dan dapat dijadikan referensi bagi guru untuk menerapkan pembelajaran menggunakan model inkuiri terbimbing berbantuan virtual laboratorium sebagai upaya meningkatkan kemampuan representasi grafik siswa.

\section{DAFTAR PUSTAKA}

Arikunto, S. 2016. Manajemen Penelitian. Jakarta: PT. Rineka Cipta

Ainsworth, S. 2006. DeFT: A conceptual framework for considering learning with multiple representations, Learning and instruction. Journal Learning and Instruction, 16 (3): 183198

Ainsworth, S. 1999. The Functions of Multiple Representations. Journal Computers and Education. 33: 131152

David, M. J., Christophe, D. J., dan Norma, A. J. 2013. The effect of representations on difficulty perception and learning of the physical concept of pressure. Themes in science and technology education. 6 (2): 91-108.
Karmila, D. D., Supeno., dan Subiki. 2019. Keterampilan inkuiri siswa sma dalam model pembelajaran inkuiri berbantuan virtual laboratory. Jurnal Pembelajaran Fisika. 8 (3): 151-158.

Kartini. 2009. Peranan Representasi dalam Pembelajaran Matematika. Prosiding dalam Seminar Nasional Matematika dan Pendidikan Matematika, 361-372.

Koentjaraningrat. $1986 . \quad$ Manajemen Penelitian. Jakarta: Aksara Baru.

Mahardika, I. K. 2013. Penerapan Model Pembelajaran Interaktif Berbasis Konsep untuk Meningkatkan Kemampuan Representasi Verbal, Matematik, dan Gambar Fisika Siswa Kelas VIII-A MTs N 1 Jember Tahun Pelajaran 2012/2013. Jurnal Pendidikan Fisika, 2(3): 272-277.

Nasution, S.B. 2000. Kemampuan Siswa dalam Memahami Grafik tentang Konsep Kinematika Gerak Lurus. Tesis tidak diterbitkan. Bandung: SPs UPI.

Puspita, R. 2008. Sistem Informasi Aplikasi Virtual Lab Pada Laboratorium Sistem Informasi Universitas Gunadarma. Proceeding, Seminar Ilmiah Nasional Komputer dan Sistem Intelijen (KOMMIT 2008) Auditorium Universitas Gunadarma, Depok, 20-21 Agustus 2008. ISSN: 1411-6286.

Roslina.1997. Proses Berpikir Logis dan Penguasaan Konsep melalui Pembelajaran dengan Pendekatan Cotextual Teaching and Learning. Tesis tidak diterbitkan. Bandung: SPs UPI.

Supeno., S. Astutik., S. Bektiarso., A. D. Lesmono dan L. Nuraini. 2018. What can students show about higher order thinking skills in physics learning. IOP Conf. Series: Earth and Environtmental Science. 